\title{
FABRICATION OF METAL MATRIX COMPOSITES USING FRICTION STIR PROCESSING: A REVIEW
}

\author{
Amit Kumar Gupta \\ Mechanical Engineering Department, ITS Engineering College, Greater Noida \\ amitgupta.me@its.edu.in
}

\begin{abstract}
: -
Composites manufacturing is one of advance manufacturing technique in the history of materials. Metal matrix composites (MMCs) have high mechanical properties and modified microstructures. Friction Stir Process is a modified technique to produce MMCs. In this Review Paper, I discussed a number of research papers and work done by different authors. Mainly in these papers, I discussed materials, Process Parameters and responses used. $\mathrm{Cu}$ (copper) and $\mathrm{Al}$ (Aluminium) matrix is used in many research papers. Aluminium and Silicon reinforcing particals are used. These particles change the property of material. These particle should be properly mixed with matrix for producing good results.
\end{abstract}

Keywords:- Metal Matrix Composites, Friction Stir Processing, Diffractometery

\section{INTRODUCTION}

The strong demand for weight reduction in car and aircraft fabrication urges the optimization of the design of products employing low weight materials. Therefore, the replacement of conventional materials by lighter metals such as aluminum alloys is highly desirable. However, aluminum alloys are not sufficiently stiff or strong for many purposes and their reinforcement is necessary. Aluminum based metal matrix composites (Al-MMCs) are outstanding candidates for these applications owning to the high ductility of the matrix and the high strength of hard reinforcing phases. Such materials are attracted towards the automobile and aerospace industries due to their better properties like wear resistance,high coefficient of friction and strength.[1-3].We can be done easily machining on metal matrix composites(MMCs)[4].

However dispersion of the reinforcements in a uniform manner in MMCs is a critical and difficult task. It should be pointed out that the existing processing techniques for fabrication of surface composites are based on liquid phase processing at high temperatures such as casting and plasma spraying. In these cases, it is hard to avoid the interfacial reaction between reinforcement and metal matrix and formation of some detrimental phases. we done the processing of composites at temperatures below melting point of substrate to avoid the difficulties. Recently, much attention has been paid to a new surface modification technique named friction stir processing.FSP(Friction Stir Process) is a solid state processing technique by which reinforced particles are uniformly distributed in the matrix.FSP is done using the same method as used in the friction stir welding (FSW) process, in which a non-consumable rotating tool with a specially designed pin and shoulder is plunged into the interface between two plates to be joined and traversed along the line of the joint[5]. Localize heat is produced by the friction between the rotating tool and the work piece leading the local temperature of the material to rise.The material undergoes intense plastic deformation resulting in significant grain refinement though FSP has been basically termed as a grain refinement technique, it is a very attractive process for also fabricating composites. Different procedures of applying reinforcement on substrate before performing FSP can be categorized as two main processes.

The First method was added reinforcements into a small amount of volatile solvent such as methanol and mixed, and applies coating on the surface of substrate, and then FSP process is carried out on the surface. Non-uniformity and limitation of preplaced layer thickness are disadvantages of this method [6]. The other alternative method is to cut one or more grooves along the FSP direction which are filled by reinforcing particles. Then, the FSP are conducted along the groove to produce a thick surface composite layer. Aluminum magnesium (Al-Mg) 5XXX series alloys have great attention in automotive industry due to their excellent high strength to weight ratio, corrosion resistance and recycling potential.Al$\mathrm{Mg}$ alloys are mainly characterized by hardness, grain size,tensile strength, wear resistance and dislocation density. Nanoparticles also produce very good effect in improving physical and chemical properties of traditionally produced fibre reinforced composites.[7-9].H.S.Arora et al.[10] gave the reviews of many paper on Micro and Nano composite(Ex-situ and In-situ) fabrication using Friction stir processing(FSP).They also showed summary of investigations(material investigated, characteristics studied and results found) made by various researchers.G. Ashok Kumar et al.[11] apply FSP process to change the morphology and distribution of particles and achieve improvement in property. AA6061/8wt. \% $\mathrm{Al}_{3} \mathrm{Zr}$ composite was produced by the in situ reaction of molten aluminum and inorganic salt $\mathrm{K}_{2} \mathrm{ZrF}_{6}$. Optical and scanning electron micrographs shows a uniform distribution of needle shape $\mathrm{Al}_{3} \mathrm{Zr}$ particles in the aluminum matrix. G Faraji et al.[12] found the effects of friction stir processing (FSP) parameters on the mechanical properties and microstructures of as-cast magnesium AZ91 alloy and also compared Grain growth and microhardness of friction-stir-processed specimens with and without nano-sized aluminium oxide $\left(\mathrm{Al}_{2} \mathrm{O}_{3}\right)$ particles. Yong X. Gan et al.[13] did a review of friction stir processing (FSP) technology and its application for microstructure modification of particle reinforced composite materials.M.Puviyarasan et al.[14] applied Friction Stir Processing (FSP) a recent grain refinement technique to disperse micron-sized $(2 \mu \mathrm{m}) \mathrm{SiCp}$ particles into aluminum alloy AA6063. Devinder Yadav et al.[15] studied Microstructure development in single and 
Asia Pacific Journals

double-pass friction stir processing on commercially pure aluminium. Min Yang et al.[16] created Nano ceramic particle reinforced composite coatings by incorporating $\mathrm{Al}_{2} \mathrm{O}_{3}$ ceramic particles into the surface of AA6061-T6 alloy plate with multiple pass friction stir processing (FSP).A.Devaraju et al.[17] studied about the Influence of addition of $\mathrm{Gr}_{\mathrm{p}} / \mathrm{Al}_{2} \mathrm{O}_{3 \mathrm{p}}$ with $\mathrm{SiC}_{\mathrm{p}}$ on wear properties of aluminum alloy 6061-T6 hybrid composites via friction stir processing. A Thangarasu et al.[18] studied microstructure and microhardness of AA1050/TiC surface composite fabricated using friction stir processing. C.F. Chen et al. [19] studied the Effect of Processing Parameters on Microstructure and Mechanical Properties of an $\mathrm{Al}-\mathrm{Al}_{11} \mathrm{Ce}_{3}-\mathrm{Al}_{2} \mathrm{O}_{3}$ In-Situ Composite Produced by Friction Stir Processing.

\section{FABRICATION OF METAL MATRIX COMPOSITES VIA FSP}

MMCs are important for structural and electrical applications. Some researchers reported the fabrication of surface metal matrix composite via FSP. G.L.You et al.[20] produced Aluminum matrix composites reinforced with nanometer-sized $\mathrm{Al}_{2} \mathrm{O}_{3}$ particles from $\mathrm{AllSiO}$ powder mixture by using friction stir processing (FSP). This study combined the hot working nature of FSP and an exothermic reaction between $\mathrm{Al}$ and $\mathrm{SiO} 2$. The $\mathrm{Al}_{2} \mathrm{O}_{3}$ particles were formed at the $\mathrm{Al} / \mathrm{SiO}_{2}$ interface and dispersed in the aluminium matrix by FSP.P.Asadi et al. [21] were added nanosized SiC and $\mathrm{Al}_{2} \mathrm{O}_{3}$ particles to as-cast $\mathrm{AZ91}$ alloy, and a surface layer with very fine grain structure was produced via friction stir processing (FSP).They found the effects of reinforcing particle types and FSP pass number on the microstructure, microhardness, and on tensile and wear properties of the developed surfaces.A.Devaraju et al.[22] studied Influence of reinforcements $\left(\mathrm{SiC}\right.$ and $\mathrm{Al}_{2} \mathrm{O}_{3}$ ) and rotational speed on wear and mechanical properties of aluminum alloy 6061-T6 based surface hybrid composites produced via friction stir processing. Parviz Asadi et al.[23] Produced AZ91/SiC composite by friction stir processing (FSP). They found that by using $5 \mu \mathrm{m} \mathrm{SiC} \mathrm{particles} \mathrm{in} \mathrm{AZ91,} \mathrm{the} \mathrm{stir} \mathrm{zone} \mathrm{grain} \mathrm{size}$ reduces and stir zone hardness increases. M. Salehi et al.[24] applied Design of experiment (DOE) to detemine the most important factors which influence ultimate tensile strength (UTS) of AA6061/SiC nanocomposites produced by friction stir processing (FSP). Effect of four factors (Tool Rotational speed, Transverse speed, Tool penetration depth and Pin profile) was investigated on UTS. By the use of Taguchi method, the optimum value of process parameters was determined. The optimum value of the Tool Rotational speed, Transverse speed, Tool penetration depth, and Pin profile were found to be $1600 \mathrm{rpm} / \mathrm{min}, 40 \mathrm{~mm} / \mathrm{min}, 0.30 \mathrm{~mm}$ and threaded type, respectively. R. Sathiskumar et al.[25] studied effect of Traverse Speed on Microstructure and Microhardness of $\mathrm{Cu} / \mathrm{B}_{4} \mathrm{C}$ Surface Composite that Produced by Friction Stir Processing(FSP). H. Sarmadi et al.[26] fabricated coppergraphite surface composites by friction stir processing(FSP) and investigated about wear and friction performances. Y.H. Sohn et al.[27] Tailored Microstructure And Properties of
Hierarchical Aluminum Metal Matrix Composites Through Friction Stir Processing.

Barmouz et al. [28] Produced copper reinforced metal matrix composite(MMC) layers using micron sized SiC particles via friction stir processing(FSP) in order to enhance surface mechanical properties. Pure copper plate with $130 \mathrm{~mm}$ length, $75 \mathrm{~mm}$ width and $6 \mathrm{~mm}$ thickness was used.5 $\mu \mathrm{m} \mathrm{SiC}$ particles were used. A groove with the dimensions of $1 \mathrm{~mm} \mathrm{x}$ $1.2 \mathrm{~mm}$ was made in the middle of the specimens.FSP tool was made of hot working steel with shoulder diameter, square pin diameter and length of 20,5 and $2 \mathrm{~mm}$. Process Parameters are Tool rotational speed (710-1120rpm) and traverse speed (40$200 \mathrm{~mm} / \mathrm{min}$ ).A processing tool was tilted by an angle of $2^{\circ}$.The specimens were clamped onto a thick St37 steel and the copper plate was fixed by the bolts.Micro-structural changes from base metal to the stirred zone were examined by optical microscope(OM) and scanning electron microscopy(SEM) and the grain size was calculated using linear intercept method.Microhardness properties of the specimens were measured on the cross section of the welds and perpendicular to the processing direction using an indentor with a $50 \mathrm{~g}$ load for $15 \mathrm{~s}$.Friction and wear properties were evaluated through a pin-on-disc test machine.Tensile test of the pure copper and the specimens FSPed with or without $\mathrm{SiC}$ particles were determined in room temperature via an instron electronic testing machine at the strain rate of $10^{-5} \mathrm{~mm} \mathrm{~s}^{-1}$.

Higher traverse speeds resulted in poor dispersion of $\mathrm{SiC}$ particles and consequently reduced the microhardness values of MMCs(Metal Matrix Composites) layers.Wear properties were improved upon addition of SiC particles. This behaviour was further supported by SEM images of wear surfaces.Results showed that the microcomposite produced by FSP having high wear resistance and higher friction coefficient with pure copper. The MMC layer produced by FSP showed lower strength and elongation than pure copper while a higher elongation was observed for the FSPed specimen without $\mathrm{SiC}$ particles.

I.S.Lee et al.[29] used Powder metallurgical route to produce metal matrix composite, after that they used FSP.The material used in this work are atomized aluminium powder and silicon powder. Mixture of $\mathrm{Al}$ and $\mathrm{Si}$ powders with desired compositions were cold compacted to form a billet. The billet was sintered at $803 \mathrm{~K}$ for $20 \mathrm{~min}$. A milling machine was adopted to carry out the FSP. The tool for FSP in this study has a shoulder of $16 \mathrm{~mm}$ diameter and tool pin is standard M1.2 × 6.

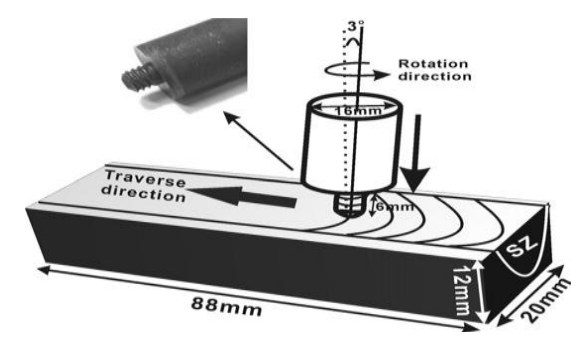

Fig no.-1 (Schematic illustrations of the friction stir process) 


\section{Asia Pacific Journals}

Schematic illustration of the friction stir process(FSP) shown in the fig. No.1.A tool rotation speed of $700 \mathrm{rpm}$ was used and traverse speed is $45 \mathrm{~mm} / \mathrm{min}$. Tool spindle angle is $3^{\circ}$.Four FSP passes were applied to billet for refinement of microstructure. The Specimen were examined with scanning electron microscope and transmission electron microscope. Tensile specimen was machined from stir zone of FSP billet with tensile axis parallel to tool traverse direction. the strain was measured using an extensometer clipped on the gauge length. Young's modulus was calculated by determining the slope of the straight line portion of tensile stress-strain curve.

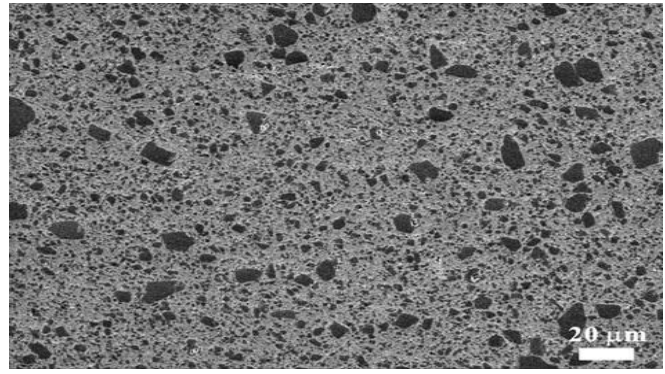

Fig No.-2

SEM/SEI of Al-30Si specimens produced by four FSP passes with tool rotating at $700 \mathrm{rpm}$ (etched by $0.5 \% \mathrm{HF}$ solution).The dark phase is Si particle.

The FSP specimens have fine $\mathrm{SiC}$ particles uniformly dispersed in the $\mathrm{Al}$ matrix. The SEM/SEI of Al-30Si specimen shown in the figure. It was also noted from microscopic observations that the stir Zone(SZ) agrees well with the calculated theoretical density. As compared with $\mathrm{Al}$ specimen, these Al-Si composites show enhanced strength and significant work hardening capacity. Both young's modulus and strength increase with increasing Si content.

Y.mazaheri et al.[30] produced $\mathrm{A} 356 / \mathrm{Al}_{2} \mathrm{O}_{3}$ surface nanocomposites by friction stir processing. The specimens used were A356-T6 $10 \mathrm{~mm}$ x 50mm x 250mm bars. Residual machining chips of $\mathrm{A} 356$ and micro and nanosized $\alpha-\mathrm{Al}_{2} \mathrm{O}_{3}$ Powders with purity of $99.9 \%$ were used for producing $\mathrm{A} 356 / \mathrm{Al}_{2} \mathrm{O}_{3}$ composite powders. We use high velocity oxyfuel(HVOF) for spraying on A356-T6 subtrates. Then plates with preplaced composite coating were subjected to FSP.Tool rotation rate, Traverse speed and tilt of spindle were $1600 \mathrm{rpm}, 200 \mathrm{~mm} / \mathrm{min}$ and $2^{\circ} . \mathrm{X}$-ray diffractometery, optical and scanning electron microscopy, microhardness and nanoindentation tests were used to characterize the samples. The results indicated that the uniform distribution of $\mathrm{Al}_{2} \mathrm{O}_{3}$ particles in $\mathrm{A} 356$ matrix by FSP process can improve the mechanical properties of specimens. The hardness and elastic modulus of the as - received A356, the sample treated by FSP without $\mathrm{Al}_{2} \mathrm{O}_{3}$ particles , surface micro- and nanocomposite specimens were about $75 \mathrm{Hv}$ and $74 \mathrm{GPa}, 69 \mathrm{Hv}$ and $73 \mathrm{GPa}, 90 \mathrm{Hv}$ and $81 \mathrm{GPa}, 110 \mathrm{Hv}$ and $86 \mathrm{Gpa}$ ,respectively.

\section{SUMMARY AND DISCUSSION}

FSP is a very successful process to produce Metal Matrix Composites. The selection of FSP parameters is a great challange to produce sound composite zone means uniform distribution of reinforcement particles in the matrix. Very fine particles used for reinforcement improve the grain structure and also improve the overall properties of the material in the form of increased young's modulus, microhardness and Tensile strength. The large amount of plastic strain produced by FSP can shear the metal powders and break the oxide film surrounding reinforcement particles, which causes contact between the matrix and the reinforcement particles and promotes the reaction. The tendency of particle agglomeration can be significantly reduced by appropriate selection of an FSP tool shoulder diameter, which is responsible for the generation of frictional and shear forces. Pretreatment of the reinforcements for improving wettability, together with multipass FSP, gives another alternative for uniform distribution of the very fine reinforcing particles in the FSP nugget zone.

The successful application of the FSP technique in generating surface and bulk composites firmly establishes it in the field of Composite manufacturing. Further research in this area and better understanding of the process characteristics and process parameters can give the way for the success of this FSP technology.

\section{References}

[1] Nikhilesh Chawla,Krishan K. Chawla(2006). Metal Matrix Composite. Springer Publisher.

[2] Clyne TW, Withers PJ (1993).An introduction to metal matrix composites. Cambridge University Press, Cambridge

[3] Karl U. Kainer. Metal Matrix Composites. Custom-Made Materials For Automotive And Aerospace Engineering. (2006) WILEY-VCH Verlag Gmbh \& Co. Kgaa, Weinheim.

[4] J. Paulo Davim. Machining of Metal Matrix Composites.Springer Publication(2012).

[5] P. Cavaliere, E. Cerri, L. Marzoli And J. Dos Santos. Friction Stir Welding Of Ceramic Particle Reinforced Aluminium Based Metal Matrix Composites. Applied Composite Materials 11: 247-258, 2004.

[6] Mishra RS, Ma ZY (2005) Mater Sci Eng R 50:1-78.

[7] Breuer O, Sundararaj U (2004) Big returns from small fibers: a review of polymer/carbon nanotube composites. Polymer Compos 25(6):630645.

[8] Lau KT, Hui D (2002) The revolutionary creation of new advanced materials - carbon nano-tube composites. Compos Part B Eng 33(4):263-277.

[9] Gojny FH, Wichmann MHG, Fiedler B, Bauhofer W, Schulte K (2005) Influence of nano-modification on the mechanical and electrical properties of conventional fibre-reinforced composites.Compos Part A Appl Sci Manuf 36(11):1525-1535.

[10] H. S. Arora, H. Singh and B. K. Dhindaw. Composite fabrication using friction stir processing - a review. Int J Adv Manuf Technol (2012) 61:1043-1055.

[11] G. Ashok Kumar, I. Dinaharan, S. J. Vijay, N. Murugan.Friction stir processing of intermetallic particulate reinforced aluminum matrix composite.Adv. Mat. Lett. 2013, 4(3), 230-234.

[12] G Faraji, O Dastani and S A A Akbari Mousavi. Microstructures and mechanical properties of Al2O3/AZ91 surface nanocomposite layer produced by friction stir processing. Journal of Engineering Manufacture 2011 225: 1331

[13] Yong X. Gan, Daniel Solomon and Michael Reinbolt. Friction Stir Processing of Particle Reinforced Composite Materials. Materials 2010, $3,329-350$ 


\section{Asia Pacific Journals}

[14] M.Puviyarasan, C.Praveen. Fabrication And Analysis Of Bulk Sicp Reinforced Aluminum Metal Matrix Composites Using Friction Stir Process. World Academy Of Science, Engineering And Technology 58 2011.

[15] Devinder Yadav and Ranjit Bauri.Microstructure development in single and double-pass friction stir processing of aluminium.Materials Science Forum Vol. 753 (2013) pp 50-53.

[16] Min Yang,Chengying Xu, Chuansong Wu,Kuo-chi Lin,Yuh J. Chao,Linan An. Fabrication of AA6061/A12O3 nano ceramic particle reinforced composite coating by using friction stir processing, J Mater Sci (2010) 45:4431-4438.

[17] A. Devaraju, A. Kumar, B. Kotiveerachari. Influence Of Addition Of Grp/A12o3p With Sicp On Wear Properties of Aluminum Alloy 6061-T6 Hybrid Composites via Friction Stir Processing. Trans. Nonferrous Met. Soc. China 23(2013) 1275-1280.

[18] A Thangarasu, N Murugan, I Dinaharan, And S J Vijay. Microstructure and microhardness of AA1050/TiC surface composite fabricated using friction stir processing. Sādhanā Vol. 37, Part 5, October 2012, pp. 579586.

[19] C.F. Chen, P.W. Kao, L.W. Chang, And N.J. Ho. Effect Of Processing Parameters On Microstructure And Mechanical Properties of an AlAl11Ce3-Al2O3 In-Situ Composite Produced by Friction Stir Processing. Volume 41A, February 2010-513-522.

[20] G.L. You, N.J. Ho, P.W. Kao. In-Situ Formation Of Al2o3 Nanoparticles During Friction Stir Processing Of AllSio2 Composite. Materials Characterization 80 (2013)1-8.

[21] P. Asadi, G. Faraji, A. Masoumi, And M.K. Besharati Givi. Experimental Investigation Of Magnesium-Base Nanocomposite Produced By Friction Stir Processing: Effects Of Particle Types And Number Of Friction Stir Processing Passes. Volume 42a, September 2011, 2820-2832.

[22] A.Devaraju, A.Kumar, A.Kumaraswamy, B.Kotiveerachari. Influence of reinforcements $(\mathrm{SiC}$ and $\mathrm{Al} 2 \mathrm{O} 3$ ) and rotational speed on wear and mechanical properties of aluminum alloy 6061-T6 based surface hybrid composites produced via friction stir processing. Materials and Design 51 (2013) 331-341

[23] Parviz Asadi, Ghader Faraji and Mohammad K. Besharati. Producing of AZ91/SiC composite by friction stir processing (FSP). Int J Adv Manuf Technol (2010) 51:247-260.

[24] M. Salehi, M. Saadatmand, J. Aghazadeh Mohandesi. Optimization Of Process Parameters For Producing Aa6061/Sic Nanocomposites By Friction Stir Processing. Trans. Nonferrous Met. Soc. China 22(2012) 1055-1063.

[25] R. Sathiskumar , N. Murugan , I. Dinaharan and S. J. Vijay. Effect of Traverse Speed on Microstructure and Microhardness of $\mathrm{Cu} / \mathrm{B} 4 \mathrm{C}$ Surface Composite Produced by Friction Stir Processing. Trans Indian Inst Met (August 2013) 66(4):333-337.

[26] H.Sarmadi, A.H.Kokabi, S.M.Seyedreihani. Friction and wear performance of copper-Graphite surface composites Fabricated by friction stir processing (Fsp). Wear 304(2013)1-12.

[27] Y.H. Sohn, T. Patterson, C. Hofmeister,1 C. Kammerer, W. Mohr, M Van Den Bergh, M. Shaeffer,J. Seaman, And K. Cho. Tailoring Microstructure And Properties Of Hierarchical Aluminum Metal Matrix Composites Through Friction Stir Processing. Jom, Vol. 64, No. 2, 2012,234-238.

[28] Mohsen Barmouz, Mohammad Kazem Besharati Givi and Javad Seyfi On the role of processing parameters in producing $\mathrm{Cu} / \mathrm{SiC}$ metal matrix composites via friction stir processing: Investigating microstructure, micro hardness, wear and tensile behaviour. Materials characterization, 62, (2011), $108-117$

[29] I.S. Lee, C.J. Hsu, C.F. Chen, N.J. Ho and P.W. Kao. Particle-reinforced aluminium matrix composites produced from powder mixtures via friction stir processing. Composites Science and Technology, 71, (2011), 693-698.

[30] Y. Mazaheri, F. Karimzadeh and M.H. Enayati. A novel technique for development of A356/A12O3 surface nanocomposite by friction stirs processing. Journal of Materials Processing Technology, 211, (2011),1614-1619. 